\title{
SURFACE TREATMENT PROPOSALS FOR THE AUTOMOTIVE INDUSTRY BY THE EXAMPLE OF 316L STEEL
}

doi:10.2478/mape-2018-0047

Date of submission of the article to the Editor: 03/2018

Date of acceptance of the article by the Editor: 07/2018

MAPE 2018, volume 1, issue 1, pp. 369-376

\author{
Dr. inż. hab. Agata Dudek \\ Mgr Barbara Lisiecka \\ Czestochowa University of Technology, Poland
}

\begin{abstract}
Nowadays, stainless steels are very interesting and promising materials with unique properties. They are characterized high mechanical strengths, high toughness and good corrosion resistance, so that can be used in many industrial sectors. An interesting alternative to steels obtained using the conventional methods is sintered stainless steel manufactured using the powder metallurgy technology. AISI 316L stainless steel is one of the best-known and widely used austenitic stainless steel. Modification of surface properties of stainless steels, in particular by applying the $\mathrm{Cr}_{3} \mathrm{C}_{2}$ coating is becoming more and more popular. The technique of atmospheric plasma spraying (APS) was used to deposit $\mathrm{Cr}_{3} \mathrm{C}_{2}-\mathrm{NiAl}$ powder on stainless steel surface. In this study presents arc surface remelting of two types of stainless steel was used by GTAW method in order to improve function and usability these materials. The results of optical microscope metallographic, hardness and scratch test are presented. The main assumption for this study was to analyze the microstructure and hardness after remelting and alloying the surface of $316 \mathrm{~L}$ steel (using GTAW method) with current intensity $50 \mathrm{~A}$.
\end{abstract}

Keywords: surface layer remelting, alloying, $316 \mathrm{~L}$ steel, $\mathrm{Cr}_{3} \mathrm{C}_{2}$ coating, gas tungsten arc welding (GTAW)

\section{INTRODUCTION}

Stainless steel are very interesting class of engineering materials that used widely in a variety of industries and environments. The austenitic stainless steel is a special type of stainless steel, which account $7080 \%$ of all stainless steel production (Moteshakker and Danaee, 2016, Vasantharaja et al., 2018)-. One of the most popular representatives of this steel is $316 \mathrm{~L}$ steel which it is an austenitic chromium nickel stainless steel containing molybdenum. Thanks to the fact that the steel is an extra-low carbon, it is possible to minimize the harmful release of carbides during welding. The addition of molybdenum improves corrosion resistance and provides increased strength at elevated temperatures. Type 316L steel has appropriate functional properties such as good mechanical strength, ductility, weldability, formability and corrosion resistance (Zareie Rajani et al., 2012, Dudek et al. 2014, Szataniak et. al., 2014). This steel is used in the automotive, biomedical, marine, aerospace, chemical and petrochemical, pharmaceutical, nuclear plants. It is used for the production of exhaust manifolds, heat exchangers, et engine parts, tanks and parts exposed to marine atmospheres, furnace parts, cargo holds in chemical tankers, etc (Peruzzo et al., 2017, Marnier et al., 2014, Ulewicz and Novy, 2016).

Powder metallurgy (PM) is a technology used for manufacturing of sintered duplex stainless steels (SDSSs). Due to the modification of the chemical composition in a wide range, it is possible to manufacture duplex steels with different microstructure. One of the biggest advantages of PM technology is the production of even small components with complex shapes while maintaining the dimensional precision and surface quality. Thanks to these possibilities, the automotive industry is the largest consumer of sintered stainless steel 
(ca. $73 \%$ of all sinters). The main products made of sintered steel are automotive parts such as exhaust system components, antilock brake systems (ABS) sensors rings, bearings, gears, filters, pumps and many others (Rajaguru et al., 217; Lailatul et al., 2017).

Sintered stainless steel manufactures using the PM technology are an alternative to steels obtained using the traditional methods such as casting and forging. This is due to lower production costs, manufacturing accuracy, surface smoothness, etc. Furthermore, porosity is important feature of sintered materials which has an impact to their mechanical properties. Parameters that affect the value of porosity are included alloy composition, time, pressure and sintering temperature and powder grain size (Chen et al., 2018). Higher values of porosity are desirable in the case orthopedic applications for designing hip joint implants. To determine the mechanical properties of austenitic stainless steels, it is to be known the both of sintering temperature and the sintering atmosphere. Sintered stainless steel should be sintered in hydrogen or argon atmospheres to have the best performance. In addition, the use of high sintering temperature (above $1200^{\circ} \mathrm{C}$ ) allows to achieve higher sintered density as well as to reduce the presence of surface oxides in order to improve the resistance to corrosion (Kurgan, 2013; Falkowska et al., 2018).

Depending on the type of phenomena used to produce surface layers, all methods can be divided into six groups. Each of these groups allows obtaining a specific surface layer, with a specific thickness and purpose, and is divided into many types (Figure 1) (Burakowski and Wierzchoń, 1995).

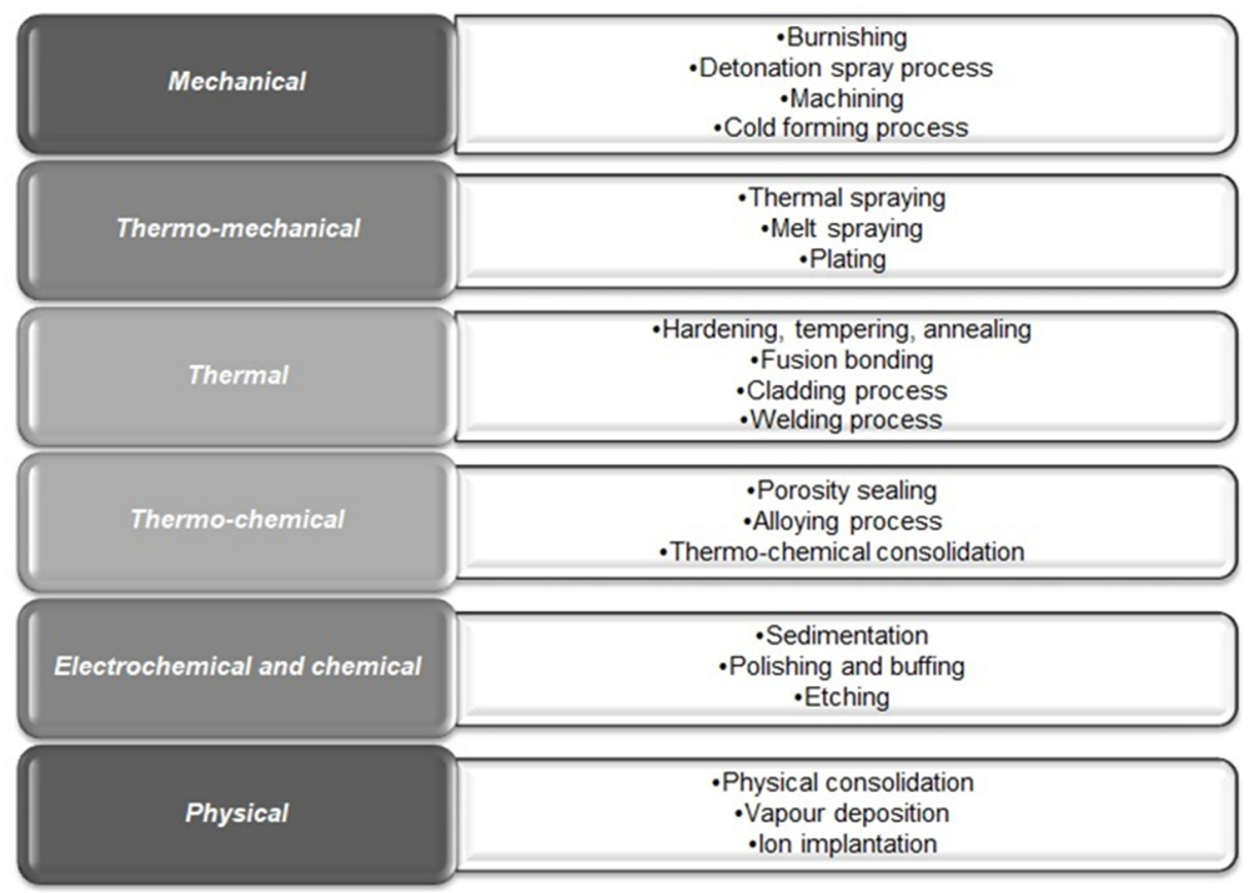

Fig. 1. Division of methods for the production of surface layers

An interesting method to obtain a surface layer with appropriate properties is surface treatment. Very often, the properties of the surface layer do not depend on the properties of the base material. Therefore, it is important to obtain structural elements that are characterized by good volume and suitable surface properties. The production of surface layers is intended to give these layers a specific structure and strength properties as well as to modify the shape, roughness or corrosion resistance. The division of surface layers into top layers and coatings is shown in Figure 2 (Zhang et al., 2016; Korkmas, 2015; Lipinski, 2015). 


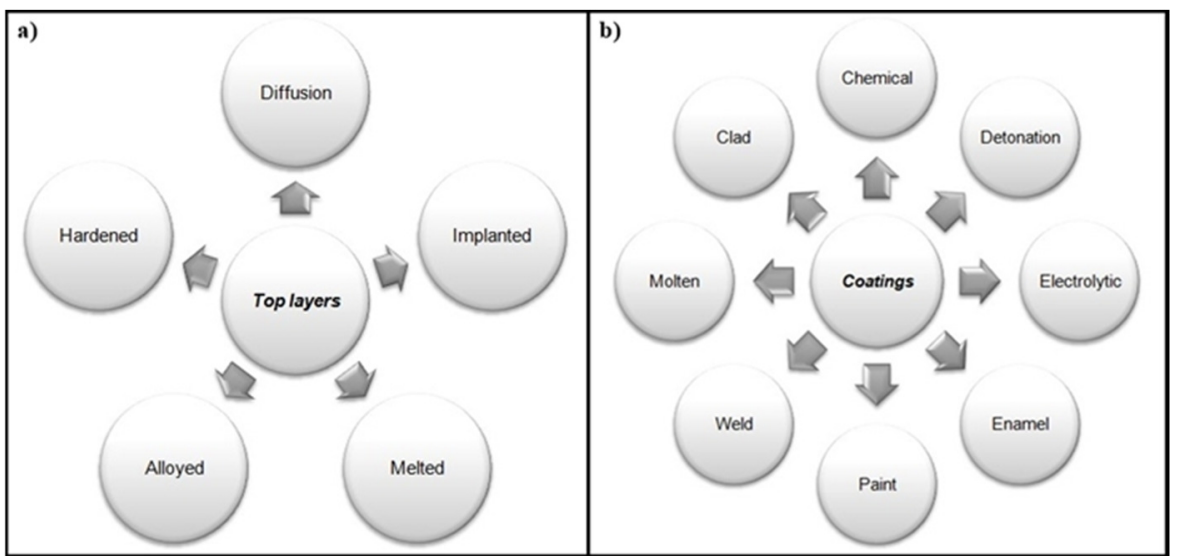

Fig. 2. Division of surface layers: a) top layers, b) coatings

Various welding techniques using concentrated sources of thermal energy allow for the modification of the surface layer of conventional corrosion-resistant steel and sintered stainless steel. One of the most interesting methods in the processing of alloys are laser technologies. They are characterized by high precision, ease in automation, but for economic reasons they belong to expensive processes. The improvement of functional properties of steels as a result of structural is changes possible through the selection of the appropriate treatment method and its parameters. The division of electron technologies due to changes occurring in the heated material is shown in Figure 3 (Adachi and Ueda, 2014; Guidoni et al., 2005).

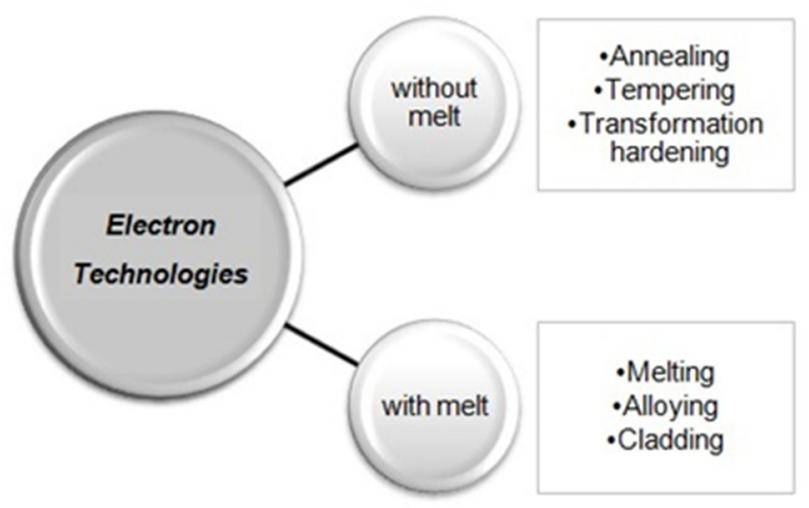

Fig. 3. Division of electron technologies

Taking into account the low cost and ease of use, the gas tungsten arc welding (GTAW) method is most often used for modification of surface layer of stainless steel, which they are showing porosity. This method consist in melting and joining the surface of the welded metal by heating them with an electric arc. The heat obtained in the welding arc is responsible for heating the melted surface above the melting point, providing heat of fusion and melting the appropriate volume of the material to be processed. The results of such modification is an increase in mechanical properties of stainless steel (Tseng and Wang 2017; Szostok et al., 2017).

\section{METHODOLOGY OF RESEARCH}

For comparison the study used $316 \mathrm{~L}$ stainless steel samples that were hot rolled plate or sintered. The specimens of sintered steels were made of water-atomized powders of $316 \mathrm{~L}$ steel about size of $150 \mu \mathrm{m}$ manufactured by Höganäs (Sweden). Chemical composition of steel powders was presented in Table 1. 
Table 1

Chemical composition of $316 \mathrm{~L}$ steel powder (\% wt.)

\begin{tabular}{|c|c|c|c|c|c|c|c|c|}
\hline \multirow{2}{*}{$\begin{array}{c}\text { Powder } \\
\text { grade }\end{array}$} & \multicolumn{9}{|c|}{ Element } \\
\cline { 2 - 9 } & $\mathbf{C r}$ & $\mathbf{N i}$ & Mo & $\mathbf{S i}$ & $\mathbf{M n}$ & $\mathbf{C}$ & $\mathbf{S}$ & $\mathbf{F e}$ \\
\hline $\mathbf{3 1 6}$ & 16.80 & 12.00 & 2.00 & 0.90 & 0.10 & 0.022 & 0.005 & Balance \\
\hline
\end{tabular}

The powders were compacted uniaxially with addition of $1 \%$ Acrawax $\mathrm{C}$ lubricant at $720 \mathrm{MPa}$. The molded pieces were sintered at the temperature of $1250^{\circ} \mathrm{C}$ for 30 minutes and then cooled down with cooling rate of $0.5^{\circ} \mathrm{C} / \mathrm{s}$. In order to significantly limit oxidation of the batch and protected from reduction of the chromium content, the whole process was carried out in the reducing atmosphere using hydrogen.

The first step was to improve functional properties of sintered stainless steel. For this purpose, using the atmospheric plasma spraying (APS) method, a chromium carbide coating of approximately $60 \mu \mathrm{m}$ was deposit on the stainless steel. The coating is performed at high temperatures, therefore in this method, the particles of $\mathrm{Cr}_{3} \mathrm{C}_{2}$ are substituted in the $\mathrm{Ni}-\mathrm{Al}$ layer (90\% wt. $\mathrm{Cr}_{3} \mathrm{C}_{2}-10 \%$ wt. NiAl). The chromium carbide coating was prepared at the following parameters: voltage: $\mathrm{Ur}=60 \mathrm{~V}$, current intensity: $\mathrm{Ir}=450 \div 500 \mathrm{~A}$, distance of the plasmatron from the surface: $80 \mathrm{~mm}$, plasma forming gases flow: argon $\sim 45 \mathrm{l} / \mathrm{min}$ and hydrogen $\sim 17$ $\mathrm{l} / \mathrm{min}$.

The next step was remelting of the surface layers rolled plate and sintered stainless steels and alloying of the coating sintered stainless steels by used GTAW technology (gas tungsten arc welding). The alloying treatment of stainless steels was carried out with constant surface scanning rate of $340 \mathrm{~mm} / \mathrm{min}$ and optimal current intensity of $50 \mathrm{~A}$. The shielding gas was argon, with the flow set at $\sim 14 \mathrm{l} / \mathrm{min}$.

The analysis of the microstructure was performed using the Olympus GX41 optical microscope. The macroscopic evaluation of sintered stainless steels after remelting or alloying process was carried out using stereo microscope Olympus SZ61. The Vickers methodology (with load of $980.7 \mathrm{mN}$ ) was employed to measure microhardness of stainless steels obtained by Shimadzu HMV-G Series.

\section{RESULTS AND DISCUSSION}

Macroscopic examinations were used for evaluate the effect of remelting and alloying on surface quality of rolled plate steel, sintered stainless steel and sintered steel with chromium carbide coating. These requirements were met for the bands alloyed using GTAW method at current intensity $50 \mathrm{~A}$. Figure 4 shows the morphology of the surface for stainless steels obtained by stereo microscope Olympus SZ61.
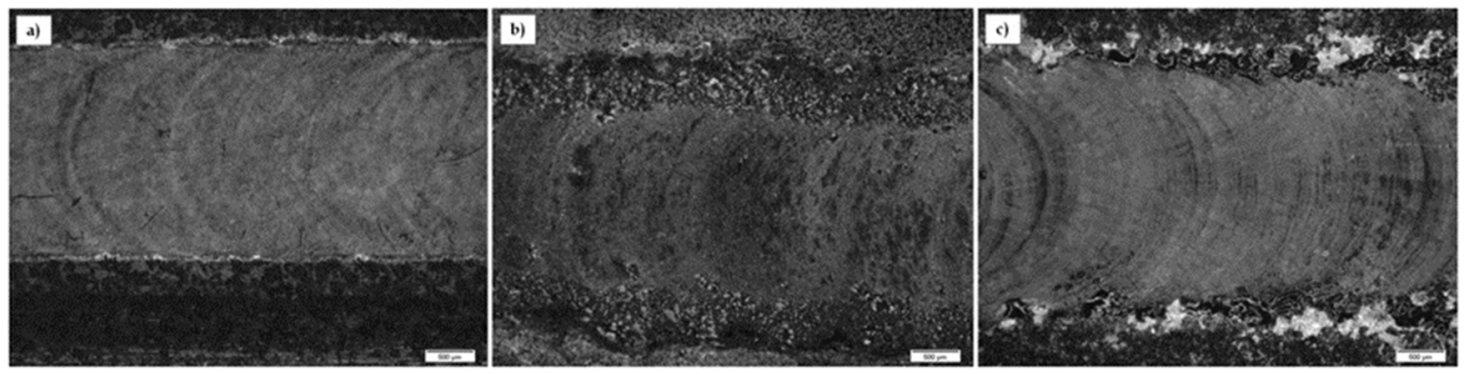

Fig. 4. Topography of the surface of austenitic stainless steel after alloying $50 \mathrm{~A}$ : a) rolled plate, b) sintered, c) with chromium carbide

The microstructures were observed using the metallographic sections etched with aqua regia. Figure 5 illustrates the microstructures obtained for austenitic stainless steels by the optical microscope Olympus GX41. The presence of pores (darker places) in the sintered steel is observed (Fig. 5b). 


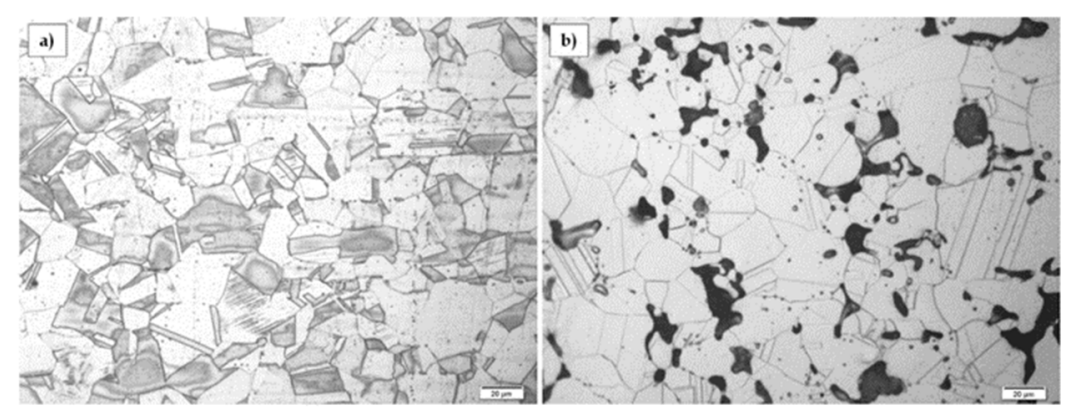

Fig. 5. Microstructure of the austenitic stainless steels: a) rolled plate, b) sintered

The chromium carbide coating obtained using plasma spraying (APS) method on the sintered stainless steel surface had thickness of around $60 \mu \mathrm{m}$. Figure 6 presents the cross-section of microstructure obtained by the optical microscope Olympus GX41. The chromium carbide coatings has characteristic elements of structure typical of APS method of deposition porosity, layers, heterogeneity.

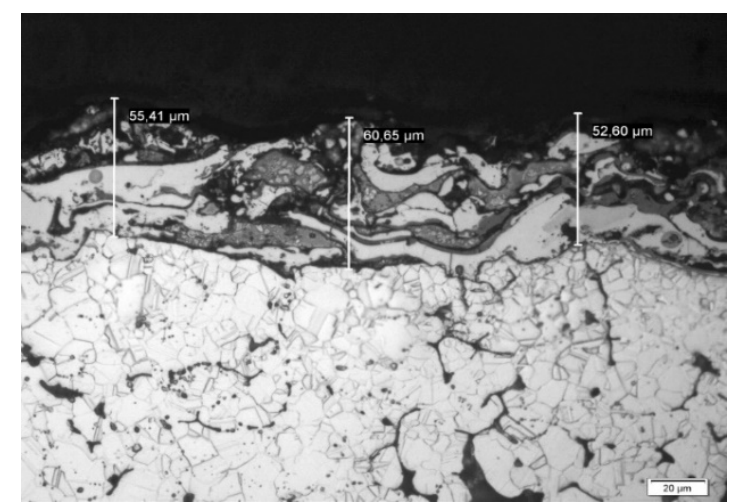

Fig. 6. Microstructure of the chromium carbide coating on sintered austenitic stainless steel after APS process

The microstructures obtained for rolled plate and sintered stainless steel after surface alloying treatment was observed using the metallographic sections etched with aqua regia. Figure 7 shows the microstructure of the surface after alloying at $50 \mathrm{~A}$ obtained for sintered stainless steel by the optical microscope Olympus GX41.

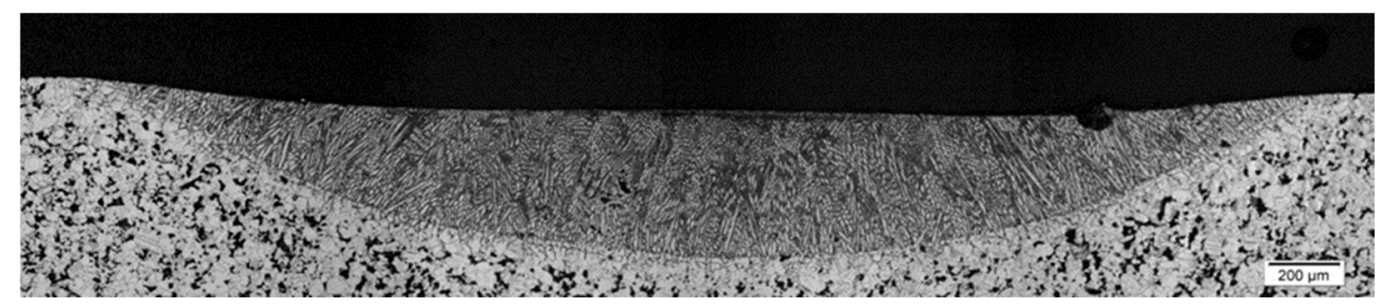

Fig. 7. Microstructure of the entire alloyed zone of sintered austenitic stainless steel after alloying $50 \mathrm{~A}$

Microstructural examinations of the surface layers, it was revealed a homogeneous cellulardendritic structure. The occurrence of column crystals oriented according to the direction of heat transfer was influenced by heat transfer and a high temperature gradient. The location of nucleation and growth of primary structure crystals took place in the transient zone. Figure 8 illustrates the microstructure of the surface after alloying at $50 \mathrm{~A}$ obtained for rolled plate stainless steel and sintered austenitic stainless steel with chromium carbide coating by the optical microscope Olympus GX41. 

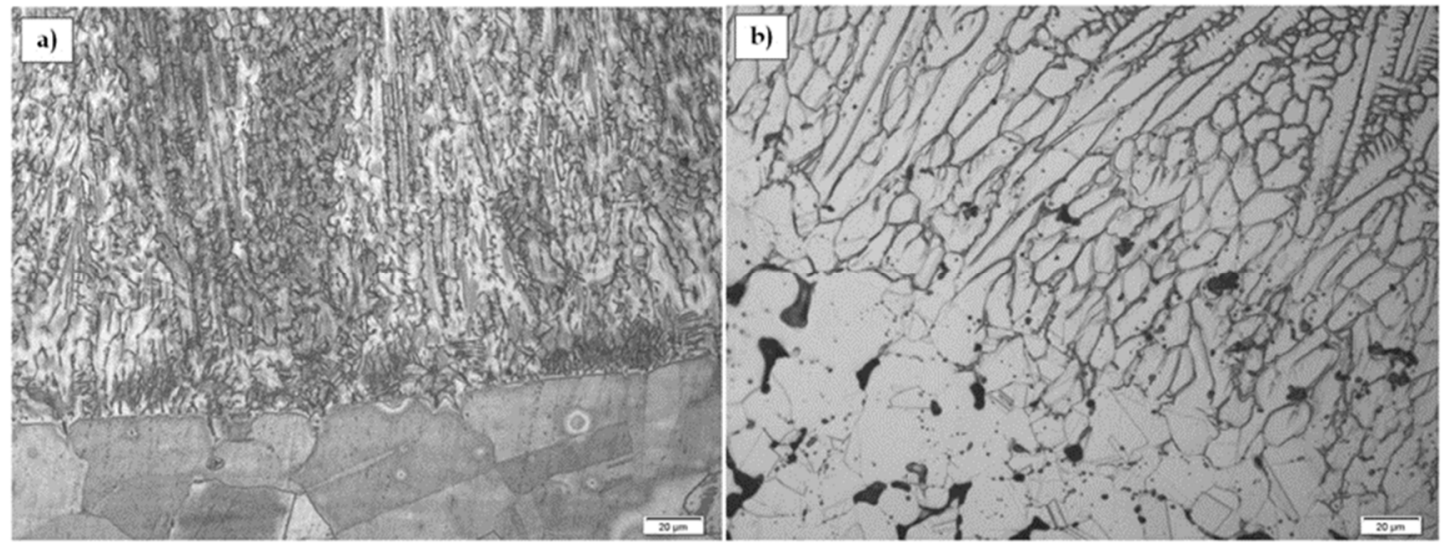

Fig. 8. Microstructure of the boundary of the alloying and heat affected zone of austenitic stainless steel: a) rolled plate, b) sintered

Hardness measurements by the Vickers method was done to evaluate mechanical properties. The results represent the mean of five measurements (Table 2). The hardness results show the improvement in strength properties after surface alloying treatment.

Table 2

Hardness of austenitic stainless steel

\begin{tabular}{|c|c|c|c|}
\hline \multirow{2}{*}{ Austenitic Stainless Steel } & \multicolumn{3}{|c|}{ Hardness [HV 0.1] } \\
\cline { 2 - 4 } & $\begin{array}{c}\mathrm{Cr}_{3} \mathbf{C}_{2}-\mathbf{N i A l} \\
\text { coating }\end{array}$ & $\begin{array}{c}\text { Alloying zone/ } \\
\text { remelting }\end{array}$ & Native material \\
\hline Rolled plate 316L steel after remelting at 50 A & - & $177 \pm 12$ & $196 \pm 11$ \\
\hline Sintered 316L steel after remelting at 50 A & - & $153 \pm 9$ & $109 \pm 15$ \\
\hline $\begin{array}{c}\text { Sintered 316L steel with } \mathrm{Cr}_{3} \mathrm{C}_{2}-\mathrm{NiAl} \text { coating after } \\
\text { alloying at 50 A }\end{array}$ & $306 \pm 6$ & $258 \pm 10$ & $105 \pm 12$ \\
\hline
\end{tabular}

Mechanical properties of the stainless steel depend on microstructure and surface treatment. The results show that GTAW method of surface treatment leads to increased hardness and thus improved functional properties. The application of $\mathrm{Cr}_{3} \mathrm{C}_{2}-\mathrm{NiAl}$ powder to the surface layers during alloying leads to even more improvement in hardness of layers obtained and an increase in homogeneity of across its thickness.

\section{CONCLUSION}

Modification of the surface layer of stainless steels consisted in the application of the chromium carbide coating to sintered stainless steel and its alloying by GTAW method. The second type of modification of the surface layer consisted in remelting of rolled plate and sintered stainless steel by GTAW method without coating. The gas tungsten arc welding (GTAW) method represents an alternative solution compared to the laser technique. The study shows that the alloying method used by the authors is a promising proposal for hardening of surface layer of stainless steels and an increase in mechanical properties.

\section{REFERENCES}

Adachi, S. and Ueda, N. (2014). Combined plasma carburizing and nitriding of sprayed AISI 316L steel coating for improved wear resistance. Surface and Coatings Technology, [online] Volume 259 (A), pp. 44-49. Available at: https://www.sciencedirect.com/science/article/pii/S0257897214005829 [Accessed 11 Jul. 2014].

Burakowski, T. and Wierzchoń, T. (1995). Inżynieria powierzchni metali. Warszawa: Wydawnictwo Naukowo-Techniczne.

Chen, X., Li, J., Cheng, X., Wang, H. and Huang, Z. (2018). Effect of heat treatment on microstructure, mechanical and corrosion properties of austenitic stainless steel $316 \mathrm{~L}$ using arc additive manufacturing. Materials Science \& Engineering A, [online] Volume 715, pp. 307-314. Available 
at: https://www.sciencedirect.com/science/article/pii/S0921509317313102 [Accessed 4 Oct. 2017].

Dudek, A., Wrońska, A. and Adamczyk, L. (2014). Surface remelting of 316L + 434L sintered steel: microstructure and corrosion resistance. Journal of Solid State Electrochemistry, [online] Volume 18, pp. 2973-2981. Available at: https://www.researchgate.net/publication/262108114_Surface_remelting_of_316L434L_sintered _steel_microstructure_and_corrosion_resistance [Accessed 4 May 2014].

Falkowska, A., Seweryn, A. and Tomczyk, A. (2018). Fatigue life and strength of 316L sintered steel of varying porosity. International Journal of Fatigue, [online] Volume 111, pp. 161-176. Available at: https://www.sciencedirect.com/science/article/pii/S0142112318300653 [Accessed 14 Feb. 2018].

Guidoni, G., Dudek, A., Patsias, S. and Anglada, M. (2005). Fracture behaviour of thermal barrier coatings after high temperature exposure in air. Materials Science and Engineering A, [online] 397, pp. 209-214. Available at: https://www.sciencedirect.com/science/article/pii/S0921509305001607 [Accessed 25 Mar. 2005].

Korkmaz, K. (2015). Investigation and characterization of electrospark deposited chromium carbidebased coating on the steel. Surface and Coatings Technology, [online] Volume 272, pp. 1-7. Available at: https://www.sciencedirect.com/science/article/pii/S0257897215003655 [Accessed 25 Apr. 2015].

Kurgan, N. (2013). Effects of sintering atmosphere on microstructure and mechanical property of sintered powder metallurgy 316L stainless steel. Materials and Design, [online] Volume 52, pp. 995-998. Available at: https://www.sciencedirect.com/science/article/pii/S0261306913005694 [Accessed 25 Jun. 2013].

Lailatul, P.H. and Maleque, M.A. (2017). Surface Modification of Duplex Stainless Steel with SiC Preplacement Using TIG Torch Cladding. Procedia Engineering, [online] Volume 184, pp. 737742. Available at: https://www.sciencedirect.com/science/article/pii/S1877705817316569 [Accessed 2 May 2017].

Lipinski, T. (2015). Morphology of Impurities in Steel after Desulfurization and Vacuum Degassing, 14th International Scientific Conference: Engineering For Rural Development, pp. 795-800.

Marnier, G., Keller, C., Noudem, J. and Hug, E. (2014). Functional properties of a spark plasma sintered ultrafine-grained 316L steel. Materials and Design, [online] Volume 63, pp. 663-640. Available at: https://www.sciencedirect.com/science/article/pii/S0261306914005020 [Accessed 2 Jul. 2014].

Moteshakker, A. and Danaee, I. (2016). Microstructure and Corrosion Resistance of Dissimilar WeldJoints between Duplex Stainless Steel 2205 and Austenitic Stainless Steel 316L. Journal of Materials Science \& Technology, [online] Volume 32, pp. 282-290. Available at: https://www.sciencedirect.com/science/article/pii/S1005030215002108 [Accessed 26 Nov. 2015].

Peruzzo, M., Beux, T.D., Ordonez, M.F.C., Souza, R.M. and Farias, M.C.M. (2017). High-temperature oxidation of sintered austenitic stainless steel containing boron or yttria. Corrosion Science, [online] 129, pp. 26-37. Available at: https://www.sciencedirect.com/science/article/pii/S0010938X16304875 [Accessed 15 Sep. 2017].

Rajaguru, J. and Arunachalam, N. (2017). Coated tool Performance in Dry Turning of Super Duplex Stainless Steel. Procedia Manufacturing, [online] Volume 10, pp. 601-611. Available at: https://www.sciencedirect.com/science/article/pii/S235197891730241X [Accessed 7 Jul. 2017].

Szabracki, P. and Lipinski, T. (2013). Effect of Aging on the Microstructure and the Intergranular Corrosion Resistance of X2CrNiMoN25-7-4 Duplex Stainless Steel. Solid State Phenomena, [online] Volume 203-204, pp. 59-62. Available at: https://www.scientific.net/SSP.203-204.59

Szataniak, P., Novy, F. and Ulewicz, R. (2014). HSLA Steels - Comparison of Cutting Techniques. METAL 2014: $23^{\text {rd }}$ International Conference on Metallurgy and Materials, pp. 778-783.

Szczotok, A., Pietraszek, J. and Radek, N. (2017). Metallographic Study and Repeatability Analysis of Gamma 'Phase Precipitates In Cored, Thin-Walled Castings Made From In713c Superalloy. Archives of Metallurgy and Materials (62)2, pp. 595-601.

Tseng, K.H. and Wang, N.S. (2017). Research on bead width and penetration depth of multicomponent flux-aided arc welding of grade $316 \mathrm{~L}$ stainless steel. Powder Technology, [online] Volume 311, pp. 514-521. Available at:

https://www.sciencedirect.com/science/article/pii/S0032591017301225 [Accessed 4 Feb. 2017].

Ulewicz, R. and Novy, F. (2016). The Influence Of The Surface Condition On The Fatigue Properties Of Structural Steel. Journal Of The Balkan Tribological Association (22)2, pp. 1147-1155.

Vasantharaja, P., Vasudevan, M. and Maduraimuthu, V. (2018). Effect of Arc Welding Processes on the Weld Attributes of Type 316LN Stainless Steel Weld joint. Transactions of the Indian Institute of Metals, [online] 71(1), pp. 127-137. Available at: https://link.springer.com/article/10.1007/s12666017-1162-2 [Accessed 29 Jun. 2017]. 
Zareie Rajani, H.R., Torkamani, H., Sharbati, M. and Raygan, Sh. (2012). Corrosion resistance improvement in Gas Tungsten Arc Welded 316 L stainless steel joints through controlled preheat treatment. Materials and Design, [online] Volume 34, pp. 51-57. Available at: https://www.sciencedirect.com/science/article/pii/S0261306911005632 [Accessed 5 Aug. 2011].

Zhang, Z., Jing, H., Xu, L., Han, Y. and Zhao, L. (2016). Investigation on microstructure evolution and properties of duplex stainless steel joint multi-pass welded by using different methods. Materials and Design, [online] Volume 109, pp. 670-685. Available at: https://www.sciencedirect.com/science/article/pii/S0264127516310164 [Accessed 22 Jul. 2016]. 